\title{
Big Data Security Problem and Its Solutions
}

\author{
Madan Mohan, Aadarsh Malviya, Anuranjan Mishra
}

\begin{abstract}
Big Data is the way to go especially for the large companies which keep a lot of information on the systems. This paper delves into the new challenges associated with big data. It points out safety challenges on Big Data as the main issues that organizations seek to address on a day-to-day basis. These challenges include securing the trusted environments, sufficient access management, performing due diligence, combating AVI vulnerabilities, and security automation. They can be solved by maintaining strict access strategies that only allow their esteemed and responsible employees to login and also set the systems in such a way that they can detect abnormalities and allow for investigations while there is still time. The paper has addressed big data challenges as well as their solutions which are always be considered in the case of the organization as they have long-term consequences if not put into consideration.
\end{abstract}

Keywords: Big Data, Systems, AVI Vulnerabilities, Security Automation, Solutions, Trusted Environments

\section{INTRODUCTION}

Big data is a word used to describe large-scale structured and unresolved data very much, it is very difficult to process data using traditional database and software technology. Volume: The quantity of produce and stored data, many factors contribute to an increase in volume, live streaming data and Storing transaction data, live streaming data, and data collections from sensors

Variety: There are data in all types of formats

Variability: Together with speed, the data flow may not be consistent with the periodic top of something height.

Complexity: When data comes from multiple sources, you also need to consider the complexity of the data. Before actual processing, the data must be linked, matched, cleaned and converted to the desired format.

\section{II. \\ NEW CHALLENGES ON BIG DATA SECURITY AND ITS SOLUTIONS}

The 21st Century business milieu regards data as its most crucial asset. Earlier on it was only the technological field that believed in the value of data but now all industries ranging from manufacturing, health, education, media and all others are already in the clique.

Manuscript received on September 08, 2021.

Revised Manuscript received on September 10, 2021.

Manuscript published on October 30, 2021.

"Correspondence Author

Madan Mohan*, Ph.D. Scholar, Department of Computer Science and Engineering, Noida International University, Greater Noida (U.P), India. Email: mmphdcse@gmail.com

Anuranjan Mishra, Professor \& Dean, GNIOT, Greater Noida (U.P), India. E-mail: amc290@gmail.com

Aadarsh Malviya, Professor, Department of Computer Science and Engineering, Noida International University, Greater Noida (U.P), India. Email: aadarsh.malviya@niu.edu.in

(C) The Authors. Published by Blue Eyes Intelligence Engineering and Sciences Publication (BEIESP). This is an open access article under the CC BY-NC-ND license (http://creativecommons.org/licenses/by-nc-nd/4.0/)

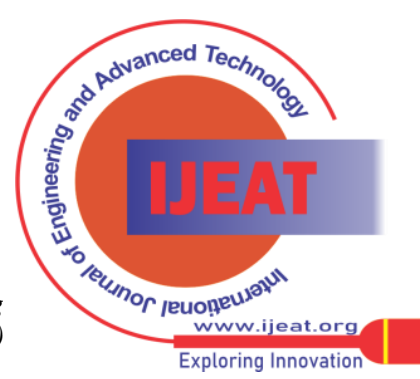




\section{Big Data Security Problem and its Solutions}

Not all employees in an organization are happy about their position in the organization and this state might lead them into accessing valuable information about the company and using it for their own self-interests (Mishra \& Kumar, 2018). Rivals and enemies most of the times use an inside person to acquire finer details of a company and use it to damage its reputation which might affect its position in the market or its ability to make significant growth. An organization using other trusted environments should, therefore, do its best to secure them from misuse both by internal and external parties. A technique referred to as "anomaly detection" is the best strategy to apply in this case as it establishes the baseline of employee interactions with the systems [3]. If the unusual behavior is detected, then the Big Data systems will automatically send alerts to management which calls for the investigation of the possibility of any intrusion or suspicious activity. However, it can sometimes be difficult to detect intrusions from the authorized staff which in many cases are responsible for the biggest downfalls of reputable firms. Another way to secure the data is by ensuring that the servers contain sensitive and valuable information have twofactor verification during access so as to reduce the number of people who have the right to use these servers.

\section{IV.}

\section{SUFFICIENT ACCESS MANAGEMENT}

Most of the severe security breaches on cloud usually occur because of inaccurate access administration. Poorly managed access systems increase the probability of employee errors while login or trying to acquire particular information during their day to day operations. The weak access patterns facilitate for future successful attacks and data breaches.

The best way to handle this situation is by enforcing the principles of least rights for workers to minimize any possible damages that come with a compromised account. The company should also allow IT managers to control the users within all the systems of the cloud and allow for a more visible and transparent procedure [4]. If all employees are aware of the details regarding the access of information in the systems or alternatively allow only a few people to exclusively login.

\section{PERFORMING DUE DILIGENCE}

Businesses are trying hard to compete and hence ending up copying each other's styles of operation. Some businesses are therefore taking on the Big Data as well as cloud computing as a way of storing and accessing data. The trend makes other organizations do it just because everyone is doing it and end up failing to execute thoroughness on their selected cloud suppliers. It is, therefore, essential for all businesses to first evaluate and examine the multiple solutions and vendors of Big Data and cloud putting into consideration their security features. The thoroughness in the selection activity enables them to work only with the best and reduce the risks of security threats and data breaches.

\section{COMBATING API VULNERABILITIES}

This factor focuses on cloud vendors as opposed to the users in the previous challenges. The vendors work directly with the providers and they expose the API to the consumer

ensuring the relations with service providers. It is, therefore, the vendor's responsibility to make sure that the API's provided is secure enough to protect the large data stored on the servers [5]. The issue can be solved by the consisten fixing of the API and scan them of vulnerabilities to reduce any security threats and it also increases confidence in the users.

\section{SECURITY AUTOMATION}

The IT staff dealing with Big Data are faced with the great challenge of dealing with sensitive information during their day-to-day activities. They are required to classify, sort out and guard classified data including Personally Identifiable Information (PII), Intellectual Property in addition to individual health data (PHI).

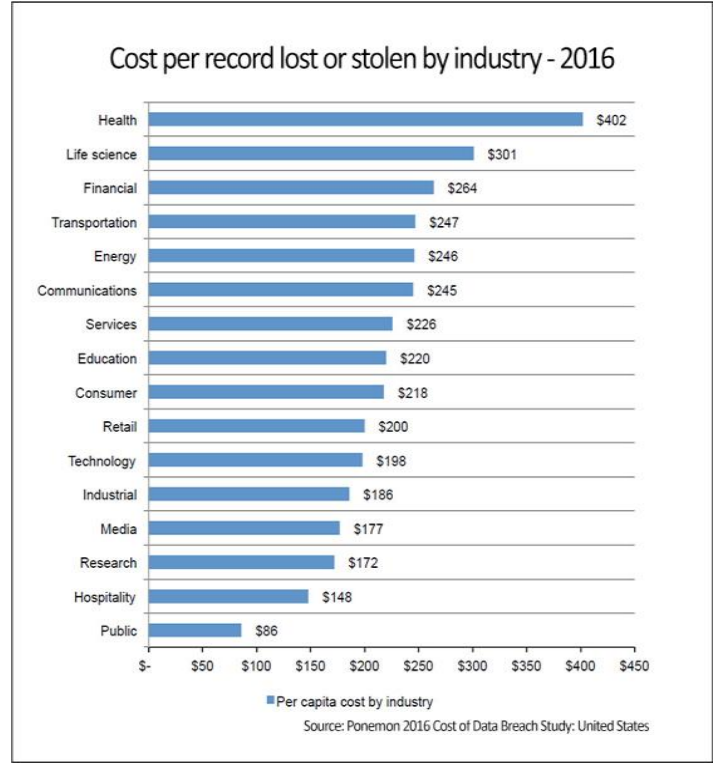

Figure 2: Illustrating the impact of data breach for different industries in the US-2016

Source: https:/www.calyptix.com/hipaa/healthcare-databreaches-expensive-average/

The best-advanced solutions including machine learning can be used in cloud computing to take over the labor-intensive activities that involve sensitive data. This method is involved in determining the way data should be stored and the methods that users access the information. The advancement is appropriate for monitoring the sensitive data and helps the IT staff as they send alerts when there are abnormal patterns detected.

\section{CONCLUSION}

apart from all the positive benefits that come with Big data, the challenges are also as pressing. These challenges reduce the trust levels of the users to invest in the modern systems of storing and accessing information. It is, however, the duty of both the users and the providers to promote privacy in Big Data. The kind of approach that each organization takes towards the safeguarding of data determines whether their information will be safe or not.

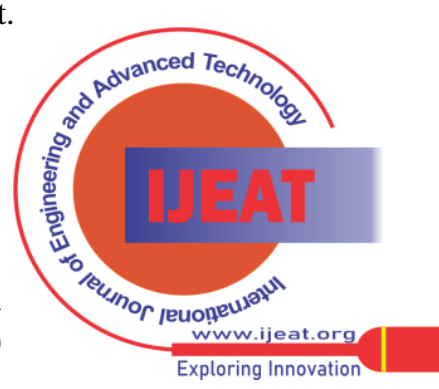


The recent problems in Big Data present a huge challenge than before which contributes to major failures and hence the need for more improved solutions to make sure that the future is bright for technological adoption in organizations.

\section{REFERENCES}

1. L., Daphne and M. A. Salem Durai. (eds.). HCI challenges and privacy preservation in big data security. New York, IGI Global, 2017.

2. M. Brojo Kishore and K. Raghvendra. Big data management and the internet of things for improved health systems. New York, IGI Global, 2018.

3. W. Yichuan, K. LeeAnn and B. Terry Anthony. Big data analytics: Understanding its capabilities and potential benefits for healthcare organizations. Technological Forecasting and Social Change, vol. 126, pp. 3-13, 2018.

4. Q. Meikang., G. Keke, T, Bhavani., T, Lixin. and Z. Hui. Proactive user-centric secure data scheme using attribute-based semantic access controls for mobile clouds in financial industry. Future Generation Computer Systems, vol. 80, no. C, pp. 421-429, 2018.

5. L. Miltiadis D., \& P. Paraskevi. Applying big data analytics in bioinformatics and medicine. New York, IGI Global, 2018.

\section{AUTHOR PROFILE}

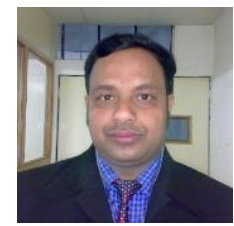

Dr. Anuranjan Mishra is Chairman of Computer society of India, Ghaziabad Chapter. He is Head MSME Business Incubation-GNIOT Centre(an Initiative of Ministry of MSME, Govt. of India), Head MSME Design Centre-GNIOT Center(an Initiative of Ministry of MSME, Govt. of India), President Institution's Innovation Council -GNIOT Centre(an Initiative of Ministry of Education, Govt. of India), Chair Unnat Bharat Abhiyan- GNIOT (an Initiative of Ministry of Education, Govt. of India), Chair Smart Campus Cloud Network- GNIOT (an Initiative of TERRI \& AICTE, New Delhi) and Dean (Research, Innovation \& Development) at Greater Noida Institute of Technology(GNIOT). He has 21 years of rich experience in academics, research and industry. He has delivered more than 25 expert talks around the world. He has more than 150 publications. He has handled research funding of $6+$ crores. He has Senior Member of ACM, CSI, IACSIT, IACNG, IRACST, CSTA, ISOC, ICE, AEE, IFETS, ISMCDM, SIGSE. His research is in Big Data, Cloud Computing, Data Science, and Algorithms. He is passionate about quality of higher education in India.

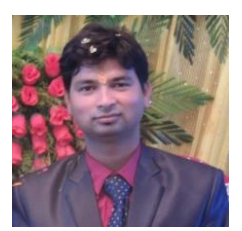

Dr. Aadarsh Malviya is a research analyst who is currently holding the designation of Assistant Professor in the department of Computer Science, School of Sciences, Noida International University. He has more than ten years of working experience during which he has covered research, academics, and Industry. His research work includes cloud computing, expert systems, soft computing, image intensification, digital image processing and artificial intelligence. He submitted his research entitled "Towards Expert Systems for Enhancing Quality of Services in Cloud Computing" in 2017 for his Doctor of Philosophy. He has been Awarded as Young Researcher in Computer Science and Engineering from Uttar Pradesh, 2019 by GOREA. He has also covered the responsibilities of training and placement department and has formed a strong base in corporate and institute relationships. He is MTA (Networking fundamental) certified and has excellence in technical background. He has developed more than hundreds web application and has students across the world who are provided assistant in technical analysis. He aspire to develop himself such that he can take his nation to the best of his place.

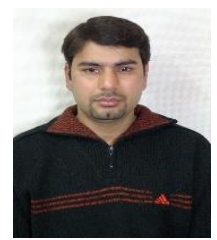

Madan Mohan is a research scholar in Noida International University, Greater Noida, Uttar Pradesh, India. Having 20 years of experience in software development and teaching at various organizations. He is doing research on security framework for big data and cloud at NIU. He has published the following papers:

- A comparison study about big data security and other technologies

- $\quad$ New challenges of big data security and its solutions

- $\quad$ Lack of privacy in big data and decentralized data in blockchain technology: going to be a big problem in future

- $\quad$ Security framework for big data log files on clouds
- $\quad$ Proposing a framework in big data to the hospitals for hypertension problem

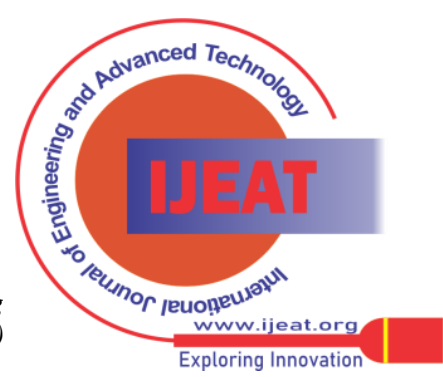

